\title{
Social Media in Turkish Cypriot Society: Power, Surveillance and the Monitoring
} Culture

\author{
Raziye Nevzat, EMU, North Cyprus
}

\begin{abstract}
This article investigates whether Turkish Cypriots perceive themselves under surveillance on social media. An online survey was conducted to 167 Turkish Cypriots to investigate the perception and factors of the social media surveillance and surveillance society in North Cyprus. Results indicated that social media surveillance perception had a significant relationship with age, gender, monthly income, collogue and superior surveillance, political party follower surveillance, and government institution surveillance. The study can be extended to Greek Cypriot sample to investigate the cultural differences in terms of surveillance perception.
\end{abstract}

Key words: Surveillance, social surveillance, social media, North Cyprus. 


\section{Introduction}

Social Media is the use of platforms like Facebook, Twitter, Foursquare, and Instagram to be informed of individuals, events and news. Facebook is the leading social network with 1.65 billion monthly users (FB, 27 April 2016). In an era where there is constant information flow among people, it is vital to look at how information flows, to whom does it flow and more importantly whether information should remain private or public. The internet in general, as engaging and entertaining, as it seems, is a source for exposed data and information of individuals in many aspects. People upload their credit card information to buy commodities, sign into social media platforms to keep in touch with one another and watch videos to stay connected with latest news. Social media is also a crucial source of information and a platform for news source for individuals. As Alice Marwick states: "These technologies are designed for users to continually investigate digital traces left by the people they are connected to through social media" ( p.378, 2012). These traces are constantly monitored by social media users and thus raises the question of how social media is related to surveillance.

For Haggerty and Ericcson "Surveillance involves collecting and analyzing information of populations to govern people” (p. 3, 2006) Throughout surveillance studies, George Orwell's novel "1984" (2003) has been used as one of the primary metaphors to indicate how surveillance on the society is constructed. Written in 1949, The Big Brother in the novel is a symbol that controls not only the corporal existence but also the thoughts of the citizens in a totalitarian way. The idea of Surveillance Society has reached its peak when Michel Foucault proposed Jeremy Bentham's Panopticon to emphasize on the concepts of surveillance, social control and power. In his book Discipline and Punish Foucault depicts the prisoner in the Panopticon as the object, "[s]he is seen, but [s]he does not see" (p. 200,1977). The common ideology of the Big Brother and Panopticon as metaphor is that they both show how power is present in societies as surveillance systems and social control mechanisms.

In 1998, the movie Truman Show has brought another dimension to the concept of surveillance. Inspired by the society that is obsessed on watching TV in the late 90's, the audience watches Truman; unaware that his life is a TV show, find out the inevitable and shocking truth that he is being watched since the day he was born. The film is transformation 
from Foucault's and Orwell's surveillance society, in which there is a supervisor watching; to a surveillance society in which the "people" are watching "people". The term surveillance society is first proposed by Gary T. Mark (1985) who referred to George Orwell's Nineteen Eighty Four and with the arrival of the digital approaches to modern life, surveillance gathered momentum with scholars like Lyon (1994,2001). Today, the same question which many scholars asked still arise with every single step of technological and digital improvement: Who is watching who now?

\section{Theoretical Framework and Hypothesis Development}

\section{Panopticon versus Synopticon in the surveillance society}

Although the ideology of surveillance is certainly formed around the panopticon metaphor, along with the technological developments other metaphors were introduced to indicate the existing social control within that time period. Mathiesen expands the discussion on Foucault's Panopticon and states that for Foucault "Panopticism represents a fundamental transformation from the situation where the many see the few to the situation where the few see the many ( p. 217,1997). Foucault's definition involves historical elements of a society which evolved from a theatrical spectacle watching the few, to the power and supervisors watching the many. Mathiesen, however, focuses on the term Synopticon as a concept that Foucault oversees, and indicates that with the rapid developments in the modern society and the mass media; few now are watching the many -VIP's, stars and reporters- and identifies themselves as a new class in the public sphere. For Mathiesen, Synopticon accelerates the viewer society and the drastic increase of Synopticon through mass media is far beyond the power that is implemented through panopticism.

As technology developed the transformation of the metaphors concerning surveillance on society continued. Lovoie, (2011) reiterates the nonknowledge of the prisoner of being watched in the panoptic system however, with the emerging technology of cameras and the virtual environment, the society can now be called superpanoptic postmodern survellience society and emphasizes that we are no longer in a private space with our self-inflicted paranoia that helps to self-regulate one in the society, just like a prisoner under control. 
Haggerty and Ericson explains (2000), surveillance as an institutional components. These components of surveillance is explicitly present in governmental institutions such as police force and authors give FBI as an example in order to show how police computer systems gather data about the people. Although the emerging TV world brought back the synopticon society in which many are watching the few, the panopticon surveillance is still present in which governmental institutions monitor people in order to collect data about the population and the society. Based on the literature above I propose the following hypothesis:

H1 There will be a significant relationship between the perception of being monitored on social media by the state authorities and the scores participants receive from the Surveillance Society survey

\section{Surveillance in Collective Society}

Christian Fuchs defines society as "interconnected subsystems, communicatively connected and networked.( p.51,2008) He cites Robins and Webster (1999) who claim that new Information and communications technology (ICT) is a continuation of panopticon because they "monitor the activities, tastes preferences of those who are networked". In order to put forward how social media became a platform for surveillance, one must look at the former versions of societal networking and social dynamics. One cannot overlook the fact that neighbor relationships and interactions are one of the main aspects of social dynamics in collective societies. Nirun (1991) evaluates neighbor relationships as an element of social dynamics and states that there are some factors that form vicinity such as "location, gossip, leisure, cultural connections, economical status, and cooperation". The aforementioned interaction left its place to social media with the emerging technology. As Lyon and Trotter reiterates, social media enables information "exchange between individuals, collaborative identity construction and friendships provide unique surveillance opportunities as users often engage with a particular audience in mind." ( p.89, 2013). This voluntary participation in social media has similarities with being in social interaction with familiar people around like neighbors yet has one difference. The collective interaction has now moved to internet. 
The socio-cultural sphere is crucial in many cultures since some cultures are explicity private, some are explicitly based on cultural communication within the society. Sinha (2014) gives Indian culture as an explicit example of the collective society and focuses on the high aspects of collectivist culture. He cites Marriot (1976) which labels the Indian society as "dividuals" within collectives rather than individuals separated from each other. "They were found to be so embedded in their in-groups that Marriot (1976) preferred to label them as "dividuals" within collectives rather than individuals separated from each other. Within their in-groups, the self-other boundary was reported to be blurred by "'affective reciprocity", "strong mutual caring", "emotional connectedness" and inhibition of "disruptive" feelings and thoughts (Roland 1980). (p.32,2014). Based on the literature above, the following hypotheses are proposed:

H2 There will be a significant relationship between the perception of being monitored on social media by the families of the participants and the scores participants receive from the Survelliance Society survey

H3 There will be a significant relationship between the perception of being monitored on social media by the friends of the participants and the scores participants receive from the Surveillance Society survey

\section{Social Media Surveillance and Turkish Cypriot Society}

Cyprus, an island in the Mediterranean, has been divided into two parts with two different cultures -Turkish and Greek- with a war in 1974 and the North part of the island ( Turkish Republic of Northern Cyprus) is only recognized by Turkey only as of today. Hence, there is no trade with any country excluding Turkey; flights are only via turkey and due to this, Turkish Cypriots live isolated on the island from the rest of the world. The isolation resulted in Turkish Cypriots living in a society closed to the outer world with embargoes and with the division of the island both cultures continued their family and neighbor relationships within the culture they were born into. The political embargos of the international world stopped direct flights to the island hence made it more difficult to travel which resulted in less travelling hence spending more time with the family and the community as well as having to 
see the same people around for many years and being well informed of one another either by talking and getting information from each other as well as monitoring the private life due to close neighbor and community relationships.

Internet; specifically social media has been an alternative way out to the outer world for Turkish Cypriots. With the transformation of villages to towns, the local culture of constantly being informed of one another still continues and with the introduction of social media to the North Part of the island, the boundaries stretched and the culture of 'being informed of one another' became easier. Consequently the aforementioned interaction among the Turkish Cypriot community and neighbors as well as being monitored by group of people and is immensely felt on social media. The collective aspect of the Turkish Cypriot community enables Facebook to be even more collective and follow what the population is doing. Wood (2009) argues that, the concept of surveillance may differ from one society to another and "Surveillance is historically, spatially and culturally located." (p.179,2009) and Marwick (2012) cites that "Social surveillance is the use of Web 2.0 sites like Twitter, Facebook and Foursquare to see what friends ,family, and acquaintances are "up to" (Joinson 2008; Tokunaga 2011). (2012:378)and points out that "Social surveillance is the ongoing eavesdropping, investigation, gossip and inquiry that constitutes information gathering by people about their peers, made salient by the social digitization normalized by social media." (p.382, 2012). She separates social surveillance on social media from other surveillance types as in social media has three characteristics

- "Power: Social surveillance assumes a model of power flowing through all social relationships.

- Hierarchy: Social surveillance takes place between individuals, rather than between structural entities and individuals.

- Reciprocity: People who engage in social surveillance also produce online content that is surveilled by others." ( p. 382,2012)

The aforementioned social dynamics of the Turkish Cypriots, due to the political situation, enabled them to adapt social surveillance to their lives on social media. People were informed 
of each other as it was an isolated community and now they are informed of each other because social media is the primary platform that connects the society to the outer world, thus majority of people in the society use it to see what everybody is doing, what everybody is interested in and what kind of engagements is everybody in the society.

The panoptic and synoptic society structure is explicit in this argument, for Turkish Cypriots monitor each other through social media to see who supports which political party, who is getting married, who is getting divorced, who is violating a rule in the society and so forth.

There is even a Facebook page called Yuh Dediklerim ; a Facebook page in which people are displayed with photographic evidence if they park on a disabled parking area, if they pollute the environment, if they violate human or animal rights but above all, if members of the government are photographed violating laws in the society. The page elevates citizen journalism as every member of the group contributes by stalking another citizen who violates the rule and proves it by uploading a photograph. The page is an evidence of how social surveillance can be constructed in a collective society through social media. Fuchs depict that “in participatory social systems power is distributed symmetrically”(p 173,2008) in people feel they can express their ideas and take part in decision making process. As much as social media encourages this kind of participatory and non-hierarchical power, it still consists the panoptic fear where surveillance might result in 'being punished'. The fear of being openly published on social media and the fact that other people are monitoring every day actions in in the Turkish Cypriot society regardless of age, gender and hierarchical position accelerated the fear of being published on Facebook because of any of the possible reasons mentioned above. The fear clearly involves the after effect of being published since employee monitoring can go far enough to be fired from the workplace as well as being blamed or being distrusted (Moussa (2015), Kovach K. A., Jordan J., Tansey K., Framinan E. (2000).

In UK it was announced that the government is paying several companies to monitor people on social media ${ }^{\mathrm{i}}$ and in the same way the political parties pay companies to conduct surveys on elections and the results are distributed through social media for publicity. Especially during elections, Turkish Cypriot population follow social media as it is one of the richest 
news source and surveys are also conducted by the political parties to build perception management. Neil Richards states that "Critically, the gathering of information affects the power dynamic between the watcher and the watched, giving the watcher greater power to influence or direct the subject of surveillance... it gives the watchers power that can be used nefariously" (p.1934-1965, 2013)

Based on this, the following hypotheses are proposed:

H4 There will be a significant relationship between the perception of being monitored on social media by the colleagues and superiors of the participants at the workplace and the scores participants receive from the Surveillance Society survey

H5 There will be a significant relationship between the perception of being monitored on social media by the political party the participants support and the scores participants receive from the Surveillance Society survey.

\section{Methodology}

\section{Participants}

Current study was conducted with 167 participants; 88 (52\%) of them were women and 79 (48\%) were men. Age groups differed from 18 to 60 . All of the participants were recruited on social media via online surveys. Majority of the participants had at least undergraduate degree or higher $(88,6 \%)$. The study targeted only Turkish Cypriots. There was an item regarding nationality differences of the participants; Turkish Cypriot, Turkish, and Other Nationalities. Participants other than Turkish Cypriots were excluded from the study.

\section{Materials}

Participants were asked to fill a short demographic questionnaire, 5 questions regarding their social surveillance in Turkish Cypriot society (Family, Friends, Collogues and Superiors, Political Party followers, and Government Institutes), and Social Surveillance Scale.

\section{Demographics}

In this section, participants were asked to fill questions regarding their age, gender, education level, monthly income and the city they live. Participants were also asked to write the social 
media platform's name they used most. However, the comparison analysis for this item was cancelled because Facebook was the most used platform with $89 \%$ response rate.

\section{Social Surveillance Scale (S.S.S.)}

The scale was created by Cemile Tokgöz (2011) to assess participants' perception on surveillance and information control by the society and the government. It has 28 items; participants were asked to read statements and indicate their thoughts with ratings from 1 (Totally disagree) to 5 (Totally agree). The study focused the surveillance scores as a whole, rather than comparing different subscales. Higher scores in S.S.S. indicated higher perception for social media surveillance. Participants' responses to 28 items were summed up and divided to 28 to calculate the mean score each participant in S.S.S. Internal consistency was 64 .

\section{Procedure}

Opportunistic and convenient sampling methods were used to recruit participants. Research was conducted in online settings. Typeform (online survey website) was used to create online survey. After forming of the survey on Typeform, social media was used for distribution of the survey. Average time for completing the online survey was 20 minutes. In total, 523 internet users visited the online survey page on Typeform, but only 217 (41\%) of them completed the survey. After the exclusion of non-Turkish Cypriot participants and outliers, 167 participants' data were analyzed for final results.

Participants were briefly informed about the study before their participation. Participants were told that their participation was voluntary and they were free to leave any time they wanted, without any explanation needed. Researchers also made sure that participants might ask questions about research if they needed more information. It almost took 20 minutes for participants to finish the survey.

523 internet users visited the online survey page on Typeform via smartphones (339 visitors), desktop and laptop computers (163 visitors), and tablet computers (20 visitors). 137 of the 
responses came from participants with smartphones, 75 participants used desktops and laptops, and 5 participants used tablet computers to complete the survey.

\section{Results}

IBM SPSS 20th version was used in the study for data analysis, and assumptions of homogeneity of variance and normality were completed for each scale. In addition, participants who have more than $+3 /-3$ z-score was also excluded from the analysis, resulting with seventeen excluded participants at total, and further analyses were completed with 167 participants. ANOVA and Correlation analyses were conducted on the data entered into SPSS. ANOVA results were measured to compare means scores depending on demographic information of the participants. Correlation coefficients were measured to see the associations among the variables.

\section{Descriptive Statistics}

The number of participants, mean scores, and ANOVA results for the variables (gender, age group, monthly income, city, and education level) can be seen in Table 1. ANOVA were conducted with participants' total score of S.S.S.

Table 1: Descriptive statistics and mean comparisons for demographic variables.

\begin{tabular}{|c|c|c|c|c|}
\hline Variables & $\mathbf{n}$ & A.S.S. & $F$ & Sig. \\
\hline Gender & 167 & 3,53 & 5,39 & ,021 \\
\hline Male & 79 & 3,59 & & \\
\hline Female & 88 & 3,48 & & \\
\hline Age & 167 & 3,53 & 2,10 &, 103 \\
\hline $18-24$ & 21 & 3,41 & & \\
\hline $25-34$ & 67 & 3,52 & & \\
\hline $35-44$ & 64 & 3,55 & & \\
\hline $45-60$ & 15 & 3,65 & & \\
\hline Education Level & 167 & 3,53 & 2,14 & ,097 \\
\hline High School & 9 & 3,69 & & \\
\hline Associate degree & 12 & 3,43 & & \\
\hline
\end{tabular}




International Conference on Communication, Media, Technology and Design
27 - 29 May 2016 Zagreb - Croatia

\section{Correlational Analyses}

A correlation analysis was conducted to see the associations among variables.. Correlation coefficients of variables can be seen in Table 2. As key findings, the correlational coefficients indicated that Social Surveillance Scale scores of the participants had a significant positive correlation with participants' gender, age group, monthly income, perceived colleague and superior surveillance, perceived political party follower surveillance, and perceived government institutions surveillance. 
International Conference on Communication, Media, Technology and Design

27-29 May 2016 Zagreb - Croatia

\begin{tabular}{|c|c|c|c|c|c|c|c|c|c|c|c|}
\hline & 1 & 2 & 3 & 4 & 5 & 6 & 7 & 8 & 9 & 10 & 11 \\
\hline 1. Social Surveillance Scale & - & & & & & & & & & & \\
\hline 2. Gender &, $179 *$ & - & & & & & & & & & \\
\hline 3. Age Group &, $184 *$ &,- 015 & - & & & & & & & & \\
\hline 4. Education level & ,018 &,- 005 &,$- 134 *$ & - & & & & & & & \\
\hline 5. Monthly Income &, $159 *$ &, 025 &, $560 * *$ &, $246 * *$ & - & & & & & & \\
\hline 6. City &,- 006 &, 001 &,- 015 &,- 134 &,- 115 & - & & & & & \\
\hline 7. Parental Surveillance &,- 014 &, 022 &,- 043 & ,046 &,- 027 &,- 020 & - & & & & \\
\hline 8. Friend Surveillance & ,090 &,- 015 &,- 095 &, 093 &,- 087 &,- 039 &, $519 * *$ & - & & & \\
\hline $\begin{array}{l}\text { 9. Collogue and Superior } \\
\text { Surveillance }\end{array}$ &, $157 *$ &,- 036 &, 015 &, 045 & ,076 &, 045 &, $567 * *$ &, $613 * *$ & - & & \\
\hline $\begin{array}{l}\text { 10. Political Party Follower } \\
\text { Surveillance }\end{array}$ & ,288** &, $218 * *$ & 0,46 &,- 007 &, 080 &, 015 &, $182 *$ &, $293 * *$ &, $421 * *$ & - & \\
\hline $\begin{array}{l}\text { 11. Government Institution } \\
\text { Surveillance }\end{array}$ &, $307 * *$ &, $179 *$ &, $227 * *$ &,- 004 &, $178 *$ &,- 099 & ,091 & ,127 &, $295 * *$ &, $359 * *$ & - \\
\hline
\end{tabular}


International Conference on Communication, Media, Technology and Design

27-29 May 2016 Zagreb - Croatia

Table 2: Correlation coefficients values (Pearson) of the variables

Note: *. Correlation is significant at 0.05 level

**. Correlation is significant at the 0.01 level 


\section{Conclusion and recommendations for further research}

This research was conducted to investigate the perceptions of surveillance in the Turkish Cypriot society and the factors that affected this perceptions. Although there was a significant positive correlation with participants' gender, age group, monthly income, perceived colleague and superior surveillance, perceived political party follower surveillance, and perceived government institutions surveillance, no significant positive relationship correlation was found with participants' perceived family and friend surveillance.

Further research could be conducted on Greek Cypriot society to investigate the relationship between the surveillance and collective society and whether the political power and state authorities is implementing surveillance on the society. 


\section{References}

Fuchs, C., Boersma, K., Albrechtslund, A., \& Sandoval, M. (2013). Internet and surveillance: The challenges of Web 2.0 and social media (Vol. 16). Routledge.

Foucault, M. (1977). Discipline and punish: The birth of the prison. Vintage.

Lavoie, D. (2011). Escaping the Panopticon: Utopia, Hegemony, and Performance in Peter Weir's The Truman Show. Utopian Studies, 22(1), 52-73.

Lyon, D. (1994). The Electronic Eye: the Rise of the Surveillance Society. Cambridge: Polity Press/Blackwell.

Lyon, D. (2001). Surveillance Society: Monitoring Everyday Life. Buckingham:

Haggerty, Kevin D., and Richard V. Ericson. 2000. The surveillant assemblage. British Journal of Sociology 51 (4):605-622.

Kevin D. Haggerty and Richard V. Ericson,(2006) eds. The New Politics of Surveillance and Visibility. University of Toronto Press.

Joinson, Adam N. 2008. "Looking at, Looking up or Keeping up with People?: Motives and Use of Facebook." In Proceeding of the Twenty-sixth Annual SIGCHI Conference on Human Factors in Computing Systems, 1027-1036.

Marriott, M. (1976). Hindu transactions: Diversity without dualism. In B. Kapferer (Ed.), Transaction and meaning (pp. 109-142). Philadelphia: Institute for the Study of Human Issues.

Marwick, Alice E. 2012. The Public Domain: Surveillance in Everyday Life. Surveillance \& Society 9(4): 378-393.

Marx, G. T. (1985). The Surveillance Society: The Threat of 1984-style Techniques. The Futurist $6,21-6$.

Marx, G. T. (2002). What's New About the" New Surveillance"? Classifying for Change and Continuity. Surveillance \& Society, 1(1), 9-29.

Mathiesen, T. (1997) The viewer society: Michel Foucault's 'Panopticon' revisited. Theoretical Criminology, 1(2): 215-234.

Moussa, M.(2015) Monitoring Employee Behavior Through the Use of Technology and Issues of Employee Privacy in America, SAGE Open, Apr 2015, 5 (2) 
Nirun, N. (1991) Sistematik Sosyoloji Yönünden Sosyal Dinamik Bünye Analizi, Ankara: Atatürk Kültür Merkezi Yayınları.

Orwell, G. (2003). Nineteen Eighty-Four. Plume.

Perrin A.. "Social Networking Usage: 2005-2015.” Pew Research Center. October 2015.

Available at: http://www.pewinternet.org/2015/10/08/2015/Social-Networking-Usage-2005$\underline{2015 /}$

Richards, Neil M., The Dangers of Surveillance ( 2013). Harvard Law Review. Available at SSRN: http://ssrn.com/abstract=2239412

Sinha, J. B. (2014). Collectivism and Individualism. In Psycho-Social Analysis of the Indian Mindset (pp. 27-51). Springer India.

The Truman Show (1998), directed by Peter Weir.

Tokgöz, C. (2011) Bilişim Çağında Toplumsal Denetim Aracı Olarak Gözetim Olgusu ve Yeni İletişim Ortamlarında Bireyin Gözetim Farkındalığı Üzerine bir Araştırma , (Unpublished Master's thesis). Marmara University, İstanbul, Turkey. Retrieved from http://www.sosyalkene.com/wp-content/uploads/2012/05/cemile-tokgoz-yl-tez.pdf

Kovach K. A., Jordan J., Tansey K., Framinan E. (2000). The balance between employee privacy and employer interests. Business and Society Review, 105, 289-298.

Tokunaga, Robert S. 2011. "Social Networking Site or Social Surveillance Site? Understanding the Use of Interpersonal Electronic Surveillance in Romantic Relationships.” Computers in Human Behavior 27 (2) (March): 705-713.

Wood, D. M. (2009) The 'Surveillance Society': Questions of History, Place and Culture, European Journal of Criminology March 2009 vol. 6 no. 2 179-194

\footnotetext{
' http://www.wired.co.uk/news/archive/2015-06/08/government-pays-companies-to-monitor-social-media-use
} 